\title{
Composição química da glicerina produzida por usinas de biodiesel no Brasil e potencial de uso na alimentação animal
}

\author{
Chemical composition of glycerin produced by biodiesel plants in Brazil and potential utilization \\ in animal feeding
}

\author{
Jackson Silva e Oliveira ${ }^{\mathrm{I}^{*}}$ Rosemar AntoniassiI $^{\mathrm{II}}$ Sidinéa Cordeiro de Freitas ${ }^{\mathrm{II}}$ \\ Marcelo Dias Müller ${ }^{\mathrm{I}}$
}

\section{- NOTA -}

\section{RESUMO}

Com a crescente produção de biodiesel no Brasil, aumenta também a produção de glicerina, co-produto dessa indústria. O principal componente da glicerina é o glicerol, altamente energético e, por isso, ela já vem sendo usada como alimento animal em vários países. $O$ objetivo deste trabalho foi avaliar a composição química da glicerina produzida por indústrias de biodiesel no Brasil e discutir seu potencial de utilização na alimentação animal. Dezesseis usinas, responsáveis por $85,1 \%$ do biodiesel produzido no país, forneceram 41 amostras para análise. Cromo, cádmio e chumbo não foram detectados em nenhuma das amostras estudadas. Apenas quatro usinas, responsáveis por $36,8 \%$ da produção, produzem glicerina que atendem os parâmetros estabelecidos pelo Ministério da Agricultura, Pecuária e Abastecimento para os teores de umidade e glicerol. Apenas uma usina, responsável por 14,1\% da produção, produz glicerina apta para uso na alimentação de ruminantes, por não utilizar sebo bovino como matéria prima para o biodiesel.

Palavras-chave: glicerol, suplemento energético, alimentação animal, ruminantes, monogástricos.

\section{ABSTRACT}

The increasing production of biodiesel in Brazil also increases glycerin production, a co-product of this industry. The main component of glycerin, glycerol, is highly energetic and because of that, glycerin is already used as animal feed in many countries. The objective of this paper was to evaluate the chemical composition of glycerin produced by biodiesel plants in Brazil and discuss its potential utilization as animal feed. Forty one samples of glycerin from sixteen biodiesel plants, that together yield $85.1 \%$ of Brazilian biodiesel, were analyzed. Chromium, cadmium and lead were not detected in any studied sample. Only four plants, that together yield $36.8 \%$ of Brazilian glycerin, comply the glycerol and moisture content levels established by the Ministry of Agriculture, Livestock and Food Supply. Only one, responsible for $14.1 \%$ of Brazilian glycerin, delivers glycerin with the potential to be used as ruminant feed once it doesn't use animal fat to produce biodiesel.

Key words: glycerol, energy supplement, animal feeding, ruminants, monogastrics.

O biodiesel é o produto da transformação química do óleo vegetal ou gordura animal através de uma transesterificação, que ocorre por adição de álcool (metanol ou etanol) na presença de um catalisador $(\mathrm{NaOH}$ ou $\mathrm{KOH})$. O produto da transesterificação é uma massa constituída por duas fases que podem ser separadas por decantação ou centrifugação. A fase mais densa é a glicerina bruta, contendo geralmente $50 \%$ de glicerol e várias impurezas, e a menos densa é o biodiesel, igualmente impregnado de impurezas. Para cada tonelada de biodiesel, são produzidos aproximadamente $100 \mathrm{~kg}$ de glicerina bruta.

O principal componente da glicerina, o glicerol, é altamente energético, está presente em alimentos e no metabolismo animal e tem potencial de uso como substituto parcial dos grãos de cereais ou outros ingredientes ricos em amido na alimentação animal (DEFRAIN et al., 2004; LAMMERS et al., 2008). Em 2010, embora sem publicação oficial, a

IEmbrapa Gado de Leite, 36038-330, Juiz de Fora, MG, Brasil. E-mail: jackoliv@ cnpgl.embrapa.br. *Autor para correspondência.

"Embrapa Agroindústria de Alimentos, Guaratiba, Rio de Janeiro, RJ, Brasil. 
glicerina oriunda do processamento do biodiesel foi autorizada na alimentação animal pelo Ministério da Agricultura e Produção Animal, desde que contenha o mínimo de $80 \%$ de glicerol e máximo de $13 \%$ de umidade (PAULE, 2012 - informação pessoal).

Considerando que diferentes matérias primas e processos podem ser utilizados na produção de biodiesel, e que a glicerina comercializada pode ter diferentes graus de pureza, este trabalho teve o objetivo de estudar a composição da glicerina proveniente de usinas de biodiesel no Brasil e identificar possíveis restrições e limitações ao seu uso na alimentação animal.

Foram analisadas 41 amostras de glicerina coletadas em 16 indústrias localizadas nas principais regiões produtoras do Brasil. A Região Norte, por ter apresentado produção inexpressiva, não enviou amostras. As amostras foram coletadas imediatamente antes de a glicerina ser direcionada para os tanques de estocagem e enviadas à Embrapa Gado de Leite, juntamente com informações referentes às matérias-primas utilizadas na usina. As análises foram realizadas na Embrapa Agroindústria de Alimentos, utilizando os métodos oficiais para analisar os parâmetros estudados. O resultado da composição química das amostras de glicerina, independentemente de sua origem, é apresentado na tabela 1 e, como média de cada usina, na tabela 2. Do total de biodiesel produzido pelas usinas participantes, $33,2 \%$ foi de usinas que trabalham exclusivamente com óleo de soja, 36,8\% das que trabalham com óleo de soja e sebo e $9,1 \%$ das que trabalham com óleos de soja e algodão. Além disso, $6 \%$ vêm de duas usinas que trabalham exclusivamente

Tabela 1 - Valores médios e variações observadas no $\mathrm{pH}$ e principais componentes da glicerina produzida em 16 usinas de biodiesel do Brasil.

\begin{tabular}{llll}
\hline Paràmetro & Média $^{1}$ & Mínimo & Máximo \\
\hline Glicerol $(\%)$ & 74,4 & 30,4 & 90,1 \\
Umidade $(\%)$ & 9,7 & 0,8 & 26,6 \\
Lipídios totais $(\%)$ & 7,8 & 0 & 37,7 \\
Cinzas $(\%)$ & 5,3 & 2,3 & 12,1 \\
Sódio $\left(\mathrm{g} \mathrm{kg}^{-1}\right)$ & 20,8 & 6,1 & 28,2 \\
Fósforo $\left(\mathrm{mg} \mathrm{kg}^{-1}\right)$ & 541 & 17 & 2.111 \\
Cálcio $\left(\mathrm{mg} \mathrm{kg}^{-1}\right)$ & 36,2 & 0 & 153 \\
pH & 7,2 & 2,3 & 12,7 \\
\hline
\end{tabular}

${ }^{1} \mathrm{~N}=41$ com sebo bovino (Tabela 2). Isso faz do óleo de soja e sebo as principais matérias-primas para produção de glicerina e biodiesel no Brasil.

$\mathrm{O}$ uso de subprodutos de origem animal na alimentação de ruminantes está proibido no Brasil, como medida de prevenção à Encefalopatia Espongiforme Bovina, também denominada EEP, ou Mal da Vaca Louca (Portaria GM/MS n. 216, de 11 de julho de 1997). A glicerina produzida em usinas que utilizam essa matéria não pode ser usada na alimentação de ruminantes, mas pode ser usada para os demais animais.

Cromo, cádmio e chumbo não foram detectados e os demais parâmetros foram bastante variáveis entre as amostras e entre as usinas participantes. Segundo THOMPSON \& HE (2006), a matéria prima é um dos fatores que influenciam na composição da glicerina. Entretanto, quando se trabalha em escala industrial, os resultados indicam que as técnicas empregadas parecem ter uma maior influência na composição final da glicerina.

Há poucas informações sobre a composição das glicerinas na literatura. SCHROËDER \& SÜDEKUM (1999) compararam três glicerinas, classificadas como de alta, média e baixa pureza, e verificaram que a umidade variou entre 1,10 e $26,8 \%$, o glicerol entre 63,3 e $99,8 \%$ e óleo entre 0,44 e $0,71 \%$ na matéria seca. Seguindo os mesmos critérios, as glicerinas analisadas neste trabalho podem ser consideradas como de baixa e média pureza. A Agência Nacional do Petróleo (ANP) exige uma qualidade mínima para o biodiesel, mas não para a glicerina. Dessa maneira, os processos pelos quais a glicerina passa após a transesterificação e, consequentemente, sua composição final, dependem exclusivamente da usina. O nível médio de lipídios totais observado nas amostras $(7,8 \%)$ é alto e torna-se preocupante, já que o método utilizado para essa determinação não especifica o tipo de lipídio presente. A princípio, os triglicerídios não representam problema na alimentação de ruminantes ou monogástricos, mas, sobre os sabões e ésteres residuais, os efeitos não são conhecidos. O nível médio de sódio presente nas amostras analisadas $\left(20,8 \mathrm{~g} \mathrm{~kg}^{-1}\right)$ sugere a presença de resíduos do catalisador $\mathrm{NaOH}$. Na formulação de dietas contendo glicerina, especialmente para aves e suínos, a concentração desse elemento deve ser tratada com atenção, uma vez que seu excesso pode comprometer o desempenho desses animais (RIBEIRO et al., 2008; KIEFER et al., 2010). 
Tabela 2 - Região, matéria prima utilizada, composição média de glicerol, umidade e lipídios totais na glicerina e participação na produção nacional de biodiesel em 2008 , pelas usinas participantes.

\begin{tabular}{|c|c|c|c|c|c|c|c|}
\hline \multirow{2}{*}{ Usina } & \multirow{2}{*}{ Região } & \multirow{2}{*}{ Matéria prima ${ }^{1}$} & \multirow{2}{*}{$\mathrm{N}^{2}$} & \multicolumn{3}{|c|}{ 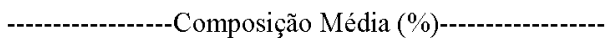 } & \multirow{2}{*}{ Produção ${ }^{3}(\%)$} \\
\hline & & & & Glicerol & Umidade & Lípídios totais & \\
\hline 1 & Centro-Oeste & $\mathrm{S}$ & 8 & 82,1 & 12,4 & 0,5 & 14,1 \\
\hline 2 & Centro-Oeste & S-Se & 5 & 76,8 & 2,1 & 11,9 & 12,4 \\
\hline 3 & Centro-Oeste & $\mathrm{S}-\mathrm{Se}$ & 5 & 85,3 & 7,4 & 1,1 & 9,6 \\
\hline 4 & Sul & $\mathrm{S}$ & 3 & 75,8 & 11,6 & 4,7 & 7,5 \\
\hline 5 & Sul & $\mathrm{S}-\mathrm{Se}$ & 3 & 83,3 & 10,5 & 0,9 & 7,4 \\
\hline 6 & Centro-Oeste & $\mathrm{S}$ & 3 & 73,1 & 18,7 & 0,1 & 6,3 \\
\hline 7 & Sudeste & $\mathrm{Se}$ & 2 & 42,9 & 3,4 & 37,0 & 6,0 \\
\hline 8 & Sudeste & S-Se & 2 & 88,0 & 6,0 & 0,1 & 5,7 \\
\hline 9 & Sul & $\mathrm{S}$ & 1 & 61,6 & 26,6 & 0,0 & 3,5 \\
\hline 10 & Nordeste & $S-A$ & 2 & 60,2 & 12,2 & 14,7 & 3,5 \\
\hline 11 & Sudeste & $S-A$ & 1 & 61,0 & 1,3 & 27,1 & 2,4 \\
\hline 12 & Centro-Oeste & $\mathrm{S}-\mathrm{Se}$ & 1 & 67,3 & 19,5 & 9,0 & 1,7 \\
\hline 13 & Nordeste & $S-A$ & 1 & 58,9 & 5,8 & 30,1 & 1,7 \\
\hline 14 & Nordeste & $S-A$ & 2 & 59,4 & 12,1 & 19,3 & 1,5 \\
\hline 15 & Centro-Oeste & $\mathrm{S}$ & 1 & 70,3 & 6,7 & 0,0 & 1,1 \\
\hline 16 & Centro-Oeste & $S$ & 1 & 66,4 & 2,5 & 26,9 & 0,7 \\
\hline
\end{tabular}

${ }^{1}$ Informado pela usina ( $\mathrm{S}=$ óleo de soja; S-Se = óleo de soja e sebo bovino; S-A = óleo de soja e óleo de algodão; Se = sebo bovino); ${ }^{2}$ Número de amostras; ${ }^{3}$ Dados das entregas nos leilões de 2008 - Disponível em $<$ http://www.anp.gov.br/?pg-54906\&m-\&t1-\&t2 -\&t3 $=\& \mathrm{t} 4=\& \mathrm{ar}=\& \mathrm{ps}=\&$ cachebust $=1311186180312$. Acesso em: 28 set. 2011 .

Pelos dados obtidos, observa-se que os componentes com maior participação na glicerina são glicerol, água e lipídios. Assim, quanto menor a retirada de umidade ou óleo, durante o processo de purificação, maior a presença desses componentes e, consequentemente, menor a participação do glicerol. (Figura 1). Para poder competir no mercado de alimentos para animais, a maioria das usinas deve ser mais eficiente na purificação de sua glicerina, especialmente na eliminação da umidade e lipídios.

Das 16 usinas estudadas, apenas 4 (Usinas $1,3,5$ e 8) atendem às exigências feitas pelo MAPA (Tabela 2). Juntas, elas foram responsáveis por 36,8\% do biodiesel entregue em 2008. Dentre elas, apenas uma (Usina 1), por trabalhar exclusivamente com óleo de soja, produz glicerina apta para uso por ruminantes.

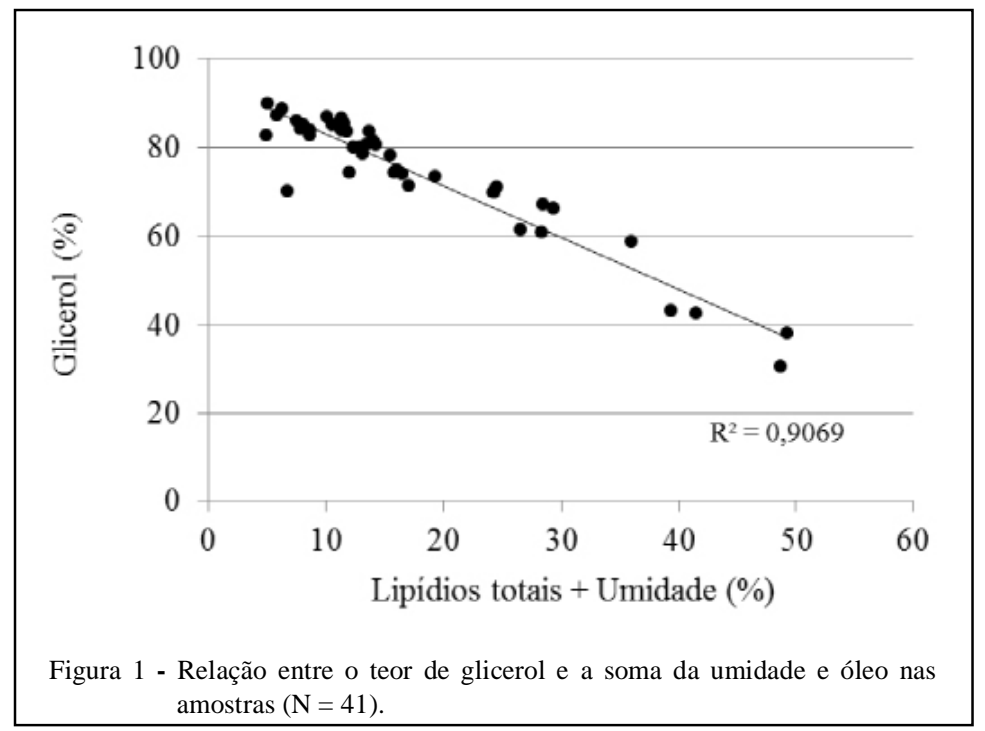

Ciência Rural, v.43, n.3, mar, 2013. 


\section{INFORMAÇÃO PESSOAL}

PAULE, B.J.A. Ministério da Agricultura Pecuária e Abastecimento/SDA/CPAA, 70043-900. Brasília, DF, Brasil. e-mail: bruno.paule@agricultura.gov.br.

\section{REFERÊNCIAS}

DEFRAIN, J.M. et al. Feeding glycerol to transition dairy cows: effects on blood metabolites and lactation performance. Journal of Dairy Science, v.87, n.12, p.4195-4206, 2004. Disponível em: <http://www. journalofdairyscience.org/article/S0022-0302(04)73564-X/fulltext〉. Acesso em: 13 out. 2011. doi: 10.3168/jds.S0022-0302(04)73564.

KIEFER, C. et al. Sódio para leitões dos 9 aos $25 \mathrm{~kg}$ mantidos sob conforto térmico. Revista Brasileira de Saúde e Produção Animal, v.11, n.2, p.386-394, 2010. Disponível em: <http:// revistas.ufba.br/index.php/rbspa /article/view/1582/975>. Acesso em: 28 nov. 2011

LAMMERS, P.J. et al. Digestible and metabolizable energy of crude glycerol for growing pigs. Journal of Animal Science, v.86, n.3, p.602-608, 2008. Disponivel em: <http://jas.fass. org/ content/86/3/602.full?>. Acesso em: 28 set. 2011. doi: $10.2527 /$ jas.2007-0453.

RIBEIRO, M.L.G. et al. Sodium levels for pullets aged between 7 and 12 weeks. Ciência e Agrotecnologia, v.32, n.4, p.1304-1310, 2008. Disponivel em: <http://www.editora.ufla. br/_adm/upload/ revista/32-4-2008_41.pdf>. Acesso em: 28 nov. 2011.

SCHRÖEDER, A.; SÜDEKUM, K.H. Glycerol as a by-product of biodiesel production in diets for ruminants. In: INTERNATIONAL RAPESEED CONGRESS, 10., 1999, Camberra. New Horizons for an Old Crop. Proceedings... Camberra: The Regional Institute, 1999. Paper n. 241. Disponivel em: <http://www.regional.org.au/ $\mathrm{au} / \mathrm{gcirc} / 1 / 241 . \mathrm{htm}>$. Acesso em: 28 set. 2011.

THOMPSON, J.C.; HE, B. Characterization of crude glycerol from biodiesel production from multiple feedstocks. Applied Engineering in Agriculture, v.22, n.2, p.261-265, 2006. Disponivel em: <http:// www.uiweb.uidaho.edu/bioenergy/NewsReleases/Published_ Glycerol_Characterization_T6.pdf>. Acesso em: 28 set. 2011. 